\title{
(2) OPEN ACCESS \\ Measuring the illicit cigarette market in Mexico: a cross validation of two methodologies
}

\author{
Belen Saenz de Miera Juarez 지, ${ }^{1}$ Luz Myriam Reynales-Shigematsu, ${ }^{2}$ \\ Michal Stoklosa (1) , ${ }^{3}$ Kevin Welding (1), ${ }^{4}$ Jeffrey Drope ${ }^{3}$
}

\begin{abstract}
- Additional material is published online only. To view please visit the journal online (http://dx.doi.org/10.1136/ tobaccocontrol-2019-055449).

${ }^{1}$ Economics, Universidad Autonoma de Baja California Sur, La Paz, Mexico ¿Departamento de Investigación sobre Tabaco, Centro de Investigación en Salud Poblacional, Instituto Nacional de Salud Pública, Cuernavaca, Mexico

${ }^{3}$ Economic and Health Policy Research, American Cancer Society, Atlanta, Georgia, USA ${ }^{4}$ Institute for Global Tobacco Control, Johns Hopkins University Bloomberg School of Public Health, Baltimore, Maryland, USA
\end{abstract}

\section{Correspondence to} Belen Saenz de Miera Juarez, Economics, Universidad Autonoma de Baja California Sur, La Paz 23080, Mexico; b.saenzdm@uabcs.mx

Received 13 October 2019 Revised 20 January 2020 Accepted 7 February 2020 Published Online First 5 March 2020
ABSTRACT

Objective To compare two methods to estimate the magnitude of the illicit cigarette trade in Mexico and to contrast these results with tobacco industry figures. Methods We used two survey methods: a smoker survey and a discarded pack survey. Data were collected in eight major cities in Mexico between November and December 2017. A total of 2396 face-to-face interviews to adult smokers were conducted and 8204 discarded packs were collected. To determine whether cigarette packs were intended for the Mexican market, we analysed pack features required by Mexican regulations and self-reported brands of the last purchase. Standard statistical tests to compare proportions were employed. Correlates of illicit cigarette use were also analysed. Results The share of cigarettes not intended for the Mexican market was $8.8 \%$ based on the analysis of discarded packs and $7.6 \%$ based on the survey of smokers, that is, the difference was small and only borderline significant overall $(p=0.055)$. Also, both results were lower than those presented by the tobacco industry (16.6\%). However, differences across methods were statistically significant for various cities.

Conclusion Our results suggest that the optimal practice for the study of illicit trade is to cross validate estimates using both the smoker survey and the littered pack survey. If resources are limited, however, our findings indicate that either method could be used because both yield similar overall results, as longs as the potential biases are considered. Also, consistent with findings from other studies, our results suggest that the tobacco industry exaggerates the scope of illicit cigarette trade.

\section{INTRODUCTION}

The tobacco industry has strong incentives to exaggerate the scope of the illicit trade of cigarettes (illicit trade thereafter). The threat of illicit trade is consistently and effectively used by the tobacco companies to argue against life-saving tobacco control policies, including plain packaging, ${ }^{1}$ marketing regulations, ${ }^{2}$ flavour bans, ${ }^{3}$ point-of-sale display bans, ${ }^{4}$ pack size restrictions ${ }^{5}$ and, foremost, tobacco tax and price policy reforms. ${ }^{6}$ The industry has been successful in using this argument to engage with policy-makers and distract them from pursuing health policy goals. ${ }^{7}$ Building on this argument, the industry has often managed to present itself as an integral partner to the government in combating illicit trade. This tactic allows them to re-enter the policy arena, where, in theory and legally, they had been previously excluded via article 5.3 of WHO Framework Convention on Tobacco Control
(FCTC). ${ }^{8}$ The industry has also been successful in getting media attention for its rhetoric and creating an echo chamber with tobacco companies and their front groups repeating similar, unsubstantiated claims about the illicit trade of cigarettes. ${ }^{10}$ Industry efforts to disseminate and publicise claims about illicit trade both among policy-makers and the public serve largely to secure their interests and impede progress in tobacco control. ${ }^{11}$

A growing number of studies expose the tobacco industry tactics around illicit trade and invalidate industry statements about the scope of the problem. ${ }^{12}$ Some of these studies evaluate the quality of the estimates presented by the tobacco industry and find that industry-funded studies are usually not peer reviewed, rarely methodologically transparent, and almost inevitably suffer from grievous problems with data collection, analytical methods and results interpretation. ${ }^{12} 13$ Other studies use one of the proven methods to estimate illicit trade and contrast their results with the numbers provided by the tobacco industry. Among the methods used in industry-independent studies, the three most popular are: (1) analysis of the gap between taxpaid sales and survey-reported consumption, (2) empty pack surveys and (3) surveys of smokers and their packs. ${ }^{14}$ The estimates of illicit trade from industry-independent studies are usually lower than those presented by the tobacco industry, suggesting that the latter exaggerate the sales of illicit cigarettes. $^{12} 13$

While the tobacco industry estimates of the illicit trade are often compared with the estimates from industry-independent studies, ${ }^{12}$ comparisons across methods in industry-independent studies are scarce. Frequently, industry-independent studies rely on only one estimation method. ${ }^{12}$ Some of those studies validate estimates from empty pack survey data collected in different settings. For example, Merriman compares data collected from littered packs in Chicago to data from a small sample of properly disposed packs. ${ }^{15}$ Similarly, John and Ross compare estimates from empty packs collected from street vendors in India to data from a small sample of littered packs on the streets. ${ }^{16}$ However, little is known about how the estimates from different methods compare. Knowing more systematically about how these methods compare can inform policy-makers and researchers about which methodologies might best serve them under particular conditions.

We know that the analysis of the gap between tax-paid sales and survey-reported consumption often yields estimates with very wide margins 
of error. Even if employed to give only the evolution of illicit trade trends, other limitations apply. First, this method is heavily dependent on the accuracy of survey-reported consumption and can be biassed by changes in smokers' under-reporting of their habits. ${ }^{17}$ Second, this method cannot distinguish if the observed gap is resulting from the inflow of illicit cigarettes to the country or the outflow of tax-paid cigarettes from the country, which makes the application of this method problematic in countries with both illegal inflow and outflow of cigarettes. Third, the method requires accurate and consistent reporting of tax-paid cigarette sales, which in many circumstances cannot be assumed by the researcher(s). Fourth, this method cannot account for legal non-tax-paying cigarettes such as those sold in duty-free zones. In contrast, the accuracy of the two methods that sample cigarette packs-the empty pack survey and the surveys of smokers' packs—can be improved by increasing the sample size. Yet, little is known about how the estimates of the two survey methods compare with each other. In principle, littered packs may be biassed towards illicit packs if littering and tax avoidance are not independent. On the other hand, smoker surveys may be biassed away from illicit packs because individuals may be less likely to report illicit activity to the enumerator. To the best of our knowledge, only one study so far compared estimates of illicit trade from an empty pack survey to the estimates from a survey of smokers. ${ }^{18}$ That study found that the estimates from the survey of smokers $(14.6 \%)$ were slightly lower than the estimates from the discarded pack survey (15.6\%). The difference between the two estimates was not statistically significant in that study, which could mean that the two methods produce comparable results, or was simply due to the study's small sample size ( $n=400$ for the survey of smokers and $n=754$ for the discarded pack survey). ${ }^{18}$

In the current study, we estimate the scope of the illicit trade of cigarettes in eight major cities in Mexico using the two survey methods-the survey of smokers and the discarded pack inspection. We compare the estimates from the two methods and also contrast them with the tobacco industry's estimates for Mexico. The large scale of the study allows a robust estimate of the illicit trade of cigarettes in Mexico. This is the first study to estimate the magnitude of illicit trade using two different methods conducted on several cities. It is also one of the first studies of illicit trade conducted using pack data in a country where a large portion of cigarettes are smoked in the form of single sticks. The results of this study can guide policy-makers who intend to implement evidence-based policies in Mexico, and also provide useful insights on the differences between the two survey methods to other researchers seeking to estimate the scope of illicit trade in their countries.

\section{COUNTRY BACKGROUND}

With the current smoking prevalence among adults estimated at $14.2 \%$ and daily smoking prevalence estimated at $8.1 \%$ in 2016, the smoking rates in Mexico are below the average in both the region of the Americas and the world. ${ }^{19}$ Yet, it is estimated that more than 10 million people still smoke in Mexico, ${ }^{20}$ which results in significant health and economic costs. There were more than 60000 tobacco-related deaths in Mexico in 2017 alone, while the economic cost of smoking, resulting from health expenditures and productivity losses, total more than US $\$ 7.4$ billion (adjusted by purchasing power parity) in 2012 or $0.4 \%$ of gross domestic product. ${ }^{21}$

Cigarette tax and price measures are very effective in reducing tobacco consumption globally, ${ }^{22}$ including in Mexico. ${ }^{23}$ However, since the excise tax on cigarettes was last increased in $2011,{ }^{24}$ inflation-adjusted cigarette prices have remained virtually unchanged (figure 1). ${ }^{25-28}$ The tobacco industry threatens that further tax increases would raise an already substantial illicit trade problem. The industry estimate of the illicit share of the cigarette market in 2012 was $16.6 \% .{ }^{29}$ Also, the most current data from Euromonitor, a market research company that is informed by the tobacco industry ${ }^{30}$ shows that illicit cigarettes accounted for $15.7 \%$ of the cigarette market in Mexico in $2017 .{ }^{26}$ Yet, it has been shown that this company manipulates its own data. ${ }^{3031}$ Specifically, data from 2011 for Mexico indicated that illicit trade had slowly increased from 3.5\% in 1997 to $6.1 \%$ in 2010 , while data from 2012 showed that the illicit cigarette market started at $9.1 \%$ in 1997 (almost three times the magnitude of the previous estimate) and increased to $21.8 \%$ in 2011. In other words, without clear substantiation Euromonitor

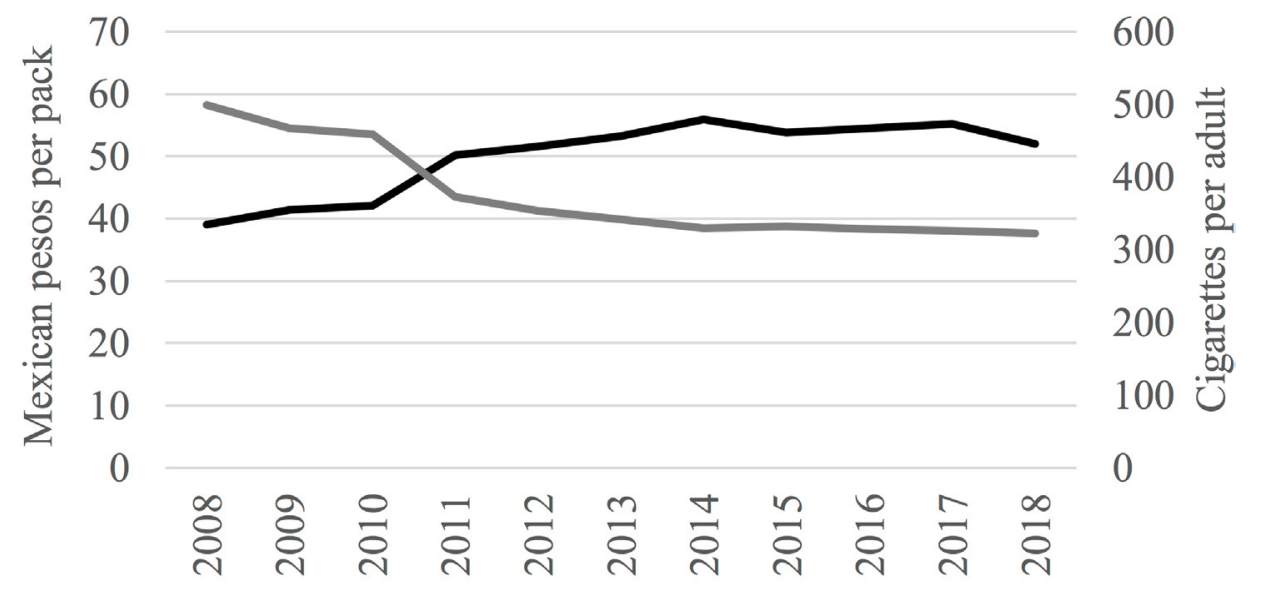

- Price per pack of Marloro (inflation-adjusted to 2018 prices)
C Cigarette sales per adult (aged 15 and over)

Figure 1 Cigarette prices and per adult cigarette sales in Mexico, 2008-2018. Source: price of factory-made cigarettes (Marlboro; pack of 20; midpriced store) in Mexico City from the Economist Intelligence Unit; inflation from the International Monetary Fund; cigarette sales from Euromonitor; number of adults from UN Population Division. 


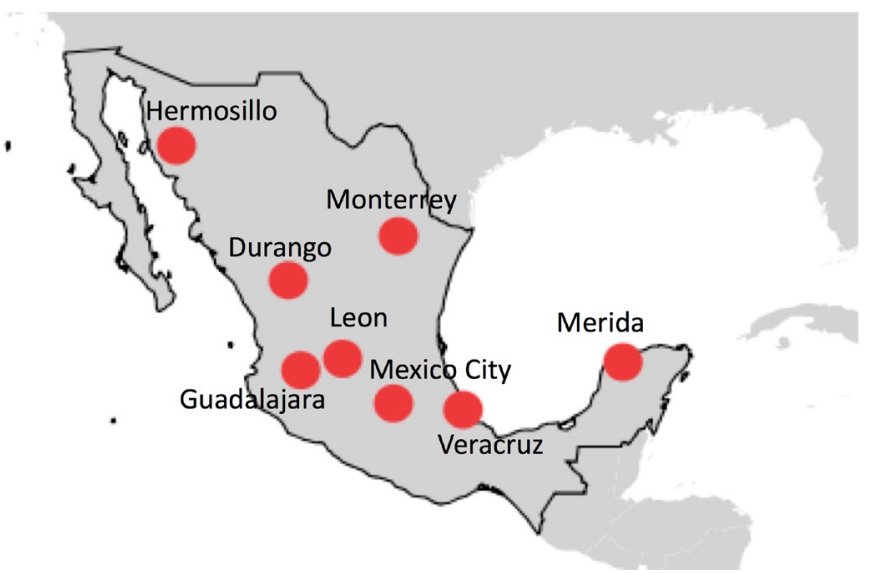

Figure 2 Location of the study cities in Mexico.

revised its estimates post facto upwards. In comparison, the estimate from government surveys indicated that the prevalence of smokers who consumed illicit cigarettes in 2011—already after the last tax increase-was only $1.4 \% .^{31}$ Therefore, industryindependent and methodologically sound and transparent estimates of illicit trade were needed to validate the industry claims and inform future revisions of the Mexican excise tax laws.

\section{METHODS}

The study was conducted in eight major cities in Mexico: Mexico City (the capital of the country), Durango (state of Durango, in the northwest), Hermosillo (state of Sonora, in the northwest), Guadalajara (state of Jalisco, in the Pacific coast), Leon (state of Guanajuato, in the centre), Merida (state of Yucatan, on the southeast coast), Monterrey (state of Nuevo Leon, in the northeast) and Veracruz (state of Veracruz, on the Gulf of Mexico) (figure 2). These cities were selected because of their high prevalence of smokers (Mexico City having the highest smoking prevalence and $35 \%$ of Mexican smokers), ${ }^{32}$ their location (at least one city in each region of the country) and preliminary evidence from a state-level representative survey (National Survey of Drugs, Alcohol and Tobacco Consumption, ENCODAT) of high prevalence of illicit cigarette smoking (Durango and Guanajuato having the highest rates of illicit cigarette smoking). The latter relied on the brand criterion that is explained in detail next and is part of an ongoing analysis of illicit trade trends.

\section{Collection of littered packs}

The Basic Geographical Areas (AGEB) of the 2010 National Population and Housing Census were used as the primary sampling units. ${ }^{33}$ The roads of each AGEB were classified according to their importance: first-order roads, second-order roads and third-order roads. The protocol assumed that all firstorder and second-order roads would be walked by the pack collectors in each AGEB. Therefore, the probability of selection into the sample for each AGEB was proportional to the length of the first-order and second-order roads in that AGEB. Based on a pilot conducted in Mexico City, a total number of 92 AGEBs were selected for the sample to satisfy a predetermined minimum walking distance of $82.8 \mathrm{~km}$ per city needed to collect 670 packs to obtain estimates with a $1.5 \%$ margin of error (see the online supplementary appendix table S1 for more information on the sample selection for the littered pack collection).

The data collection was conducted between 13 November and 5 December 2017 by the National Institute of Public Health (INSP) using volunteers recruited by government's National
Office for Tobacco Control and the State Councils against Addictions. The teams used previously prepared maps to cover all the necessary roads. Each pack found along the mapped route was placed in a plastic bag, labelled with a unique serial number and the collection place was marked on the map. Because in some cities (Durango, Hermosillo and Leon) the density of littered packs was significantly higher than expected from the pilot study, only a portion of relevant roads were covered in those cities. Among the 31 AGEBs that were not fully covered, the collectors covered at least one-third of the relevant roads. The percentage coverage of all roads in each of those AGEBs was used to calculate the expansion factor needed to estimate the total number of packs and the number of illicit packs in each of those not-fully-covered AGEBs. A total of 8204 packs were collected, that is, 1026 per city or 89 per AGEB, on average.

\section{Survey of smokers}

Using information about the prevalence of smokers per city, ${ }^{32}$ a total of 2396 adult smokers (age 18 and older) were sampled across the 8 participating cities. The quota of smokers was distributed among 236 randomly selected AGEBs, within which two blocks (manzanas) were randomly selected to conduct the interviews. Interviewers approached all households along predefined routes around each of the selected blocks and interviewed one randomly selected smoker through a Kish selection grid per household. On average, 5 interviews per block (ie, 10 per AGEB) were conducted (see the online supplementary appendix table S2 for more information on the sample selection for the survey of smokers).

The questionnaire was designed by the INSP with input from the extended research team who had participated in similar smoker surveys previously. The smokers were asked about their smoking intensity (cigarettes per day or week), and their last cigarette purchase (quantity, price, brand and place of purchase). Their socioeconomic characteristics were also collected. For smokers who had their pack and agreed to show it to the interviewers, information about the brand, health warnings and appropriate markings was also collected from that pack. The field work took place between 16 November and 5 December 2017. It was conducted by the market research company, Parametría S.A.- which has never had an affiliation with the tobacco industry-and supervised by INSP.

\section{Identification of illicit cigarettes}

The 8204 collected packs from the littered packs study were returned to the INSP research office where pack information was coded to a database. To evaluate the process, approximately $10 \%$ of the packs (825 packs) were randomly selected, stratifying by city, and those packs were coded by a second coder. The collected information matched $99.7 \%$ of the time.

Three pack features required by the General Law for Tobacco Control (LGCT) determined whether the pack was intended for the Mexican market: (1) an approved pictorial health warning covering $30 \%$ of the front surface of the pack, (2) an approved text-only health warning covering $100 \%$ of the back surface of the pack and (3) the message 'For exclusive sale in Mexico' ('Para venta exclusiva en México') printed on one of the side panels of the pack. ${ }^{34}$ Packs with any of those characteristics missing were classified as packs not intended for the Mexican market. In case of packs where 1 (1094 packs; $13.25 \%)$ or 2 (888 packs, $10.76 \%$ ) characteristics could not be evaluated due to pack damage, only the visible characteristics were considered. 
Table 1 Distribution of smokers aged 18 and above in the survey of smokers in eight Mexican cities, by selected sociodemographic characteristics

\begin{tabular}{|c|c|c|c|c|}
\hline \multirow[b]{2}{*}{ Characteristics } & \multicolumn{2}{|c|}{ Weighted numbers } & \multicolumn{2}{|c|}{$\begin{array}{l}\text { Unweighted } \\
\text { numbers }\end{array}$} \\
\hline & $\%$ & $95 \% \mathrm{Cl}$ & $\%$ & $n$ \\
\hline Total & 100 & & 100 & 2396 \\
\hline \multicolumn{5}{|l|}{ Gender } \\
\hline Female & 38.4 & (35.0 to 42.0 ) & 31.3 & 751 \\
\hline Male & 61.6 & (58.0 to 65.0$)$ & 68.7 & 1645 \\
\hline \multicolumn{5}{|l|}{ Age } \\
\hline $18-24$ & 18 & (15.2 to 21.1$)$ & 16.6 & 398 \\
\hline $25-44$ & 45.7 & (42.3 to 49.2 ) & 46.3 & 1109 \\
\hline $45-64$ & 29 & (26.0 to 32.2 ) & 29.0 & 695 \\
\hline 65 and more & 7.3 & (5.9 to 9.0$)$ & 8.1 & 194 \\
\hline \multicolumn{5}{|l|}{ Education* } \\
\hline Without formal education & 1.6 & (1.1 to 2.4 ) & 2.1 & 49 \\
\hline Primary & 19.7 & (17.2 to 22.5$)$ & 23.4 & 561 \\
\hline Middle school & 38.3 & (35.0 to 41.8 ) & 35.9 & 859 \\
\hline High school & 28.4 & (25.4 to 31.6 ) & 28.5 & 683 \\
\hline University and postgraduate & 11.9 & (9.8 to 14.5 ) & 10.1 & 242 \\
\hline \multicolumn{5}{|l|}{ Employment } \\
\hline Employed & 63.8 & (60.3 to 67.2 ) & 68.8 & 1639 \\
\hline Inactive & 32.8 & (29.5 to 36.3 ) & 27.9 & 665 \\
\hline Unemployed & 3.4 & (2.3 to 5.0$)$ & 3.3 & 78 \\
\hline \multicolumn{5}{|l|}{ Socioeconomic levelt } \\
\hline High & 20.3 & (17.8 to 23.1$)$ & 20.2 & 484 \\
\hline Medium & 36.7 & (33.5 to 40.0$)$ & 37.1 & 889 \\
\hline Low & 43 & (39.6 to 46.5 ) & 42.7 & 1023 \\
\hline \multicolumn{5}{|c|}{$\begin{array}{l}\text { "Education corresponds to the last grade completed. } \\
\text { †To build the socioeconomic level indicator, the Mexican Association of Market Research } \\
\text { Agencies } 8 \times 7 \text { method was used, which consists of assigning scores based on eight variables } \\
\text { on characteristics of the household (number of rooms, number of bathrooms, whether there } \\
\text { is a shower in any of the bathrooms, number of light bulbs, floor type, number of cars, } \\
\text { whether the household has a gas or electric stove) and the head of the household (highest } \\
\text { grade completed) collected with the survey of smokers. }{ }^{41} 95 \% \mathrm{Cl} \text { : confidence interval at } 95 \% \\
\text { estimated using a normal approximation and sampling weights. } \\
n \text {, number of observations. }\end{array}$} \\
\hline
\end{tabular}

The percentage of smokers who showed their packs in the survey of smokers was relatively low (29\%), presumably because a large portion of smokers in Mexico purchase their cigarettes in single sticks $(48.1 \%$ or nearly half of the smokers according to a recent survey). ${ }^{32}$ Therefore, for this method, rather than relying on the pack characteristics, only the self-reported brand of the last-purchased cigarettes determined whether the pack was intended for the Mexican market. Specifically, with the list of brands approved on the Mexican market published by the Tax Administration Service (SAT) ${ }^{35}$ and a list of illicit cigarette brands in Mexico published by the Federal Commission for the Protection against Sanitary Risks (Cofepris) ${ }^{36}$ the cigarettes with brands that do not appear on the Cofepris list but are listed by SAT were classified as packs intended for the Mexican market. Only eight brands appeared in both Cofepris and SAT lists and five did not appeared in either of the two lists; cigarettes with these brands were classified as illicit.

\section{RESULTS}

Table 1 summarises the characteristics of smokers interviewed in the survey of smokers. These characteristics closely resemble the characteristics of smokers in Mexico as captured by national surveys such as ENCODAT, ${ }^{32}$ except for some difference in the proportion of daily versus occasional smokers that may be related to differences in the target population. Indeed, the sample of other only-smoker survey conducted in six main cities, the ITC Mexico survey, also comprised relatively more daily than occasional smokers. ${ }^{37}$

Table 2 summarises the findings from both surveys. Based on the collection of littered packs, we estimate that the share of packs not intended for the Mexican market (illicit) was $8.8 \%$ (ranging from $0.3 \%$ in Hermosillo to $27.5 \%$ in Leon). Using the data from the survey of smokers, we estimate that the share of illicit cigarettes was $7.6 \%$ (ranging from $1.5 \%$ in Merida to $22.5 \%$ in Leon). The difference in estimates from both methods for the total is about 1.2 percentage points and only borderline significant $(\mathrm{p}=0.055)$. Both results were considerably lower than those presented by the tobacco industry $(16.6 \%){ }^{29}$

The survey of littered packs found that, among the packs with all three features visible, the proportions of packs without the proper front health warnings, the proper back health warnings and the proper destination message were similar $(p>0.05)$, meaning that if a pack was lacking one of the features, it was very likely to be lacking all three features as well (online supplementary appendix table S3). Likewise, we analysed a larger list of 10 pack features required by the LGCT in a random subsample of littered packs $(n=893)$ and found that the estimates of illicit cigarette use barely changed (results not shown); specifically,

Table 2 Illicit cigarettes in Mexico by city

\begin{tabular}{|c|c|c|c|c|c|}
\hline & \multicolumn{3}{|l|}{ Survey of smokers } & \multirow{2}{*}{\multicolumn{2}{|c|}{$\begin{array}{l}\text { Collection of littered packs } \\
\text { Illicit share of the total consumption of } \\
\text { cigarettes }\end{array}$}} \\
\hline & \multirow{2}{*}{$\begin{array}{l}\begin{array}{l}\% \text { of smokers who use illicit } \\
\text { cigarettes }\end{array} \\
\text { Estimate }\end{array}$} & \multicolumn{2}{|c|}{$\begin{array}{l}\text { Illicit share of the total consumption of } \\
\text { cigarettes }\end{array}$} & & \\
\hline & & Estimate & $95 \% \mathrm{Cl}$ & Estimate & $95 \% \mathrm{Cl}$ \\
\hline Mexico City* & $2.2 \%$ & $2.4 \%$ & (0.6\% to $4.0 \%)$ & $6.6 \%$ & ( $5.1 \%$ to $8.6 \%)$ \\
\hline Durango & $11.6 \%$ & $16.5 \%$ & (8.7\% to $25.9 \%$ ) & $17.5 \%$ & (15.4\% to $19.8 \%)$ \\
\hline Guadalajara* & $5.3 \%$ & $5.6 \%$ & (2.7\% to $11.5 \%)$ & $10.6 \%$ & (8.7\% to $13.0 \%$ ) \\
\hline Merida* & $5.2 \%$ & $1.5 \%$ & $(0.6 \%$ to $3.2 \%)$ & $7.8 \%$ & (6.4\% to $9.6 \%)$ \\
\hline Monterrey* & $3.6 \%$ & $5.2 \%$ & (2.6\% to $10.6 \%)$ & $1.4 \%$ & ( $0.7 \%$ to $2.7 \%)$ \\
\hline Veracruz & $0.9 \%$ & $2.6 \%$ & $(0.3 \%$ to $6.6 \%)$ & $1.0 \%$ & (0.5\% to $2.1 \%$ ) \\
\hline Total & $5.0 \%$ & $7.6 \%$ & (6.5\% to $8.7 \%$ ) & $8.8 \%$ & (8.2\% to $9.4 \%$ ) \\
\hline
\end{tabular}

For the survey of smokers, illicit market share is calculated based on self-reported intensity of smoking. The totals are weighted by the number of smokers in each city.

${ }^{*} \mathrm{P}<0.05$ in two-tailed test for comparison of two proportions with no sampling weights; $95 \% \mathrm{Cl}$ : confidence interval at $95 \%$ estimated using a normal approximation and sampling weights. 
Table 3 Correlates of illicit cigarette consumption in Mexico (dependent variable $=1$ if smoker uses illicit cigarettes)

\begin{tabular}{|c|c|c|}
\hline Characteristics & ORs & Standard errors \\
\hline \multicolumn{3}{|l|}{ Gender } \\
\hline Male & 1.267 & -0.34 \\
\hline \multicolumn{3}{|l|}{ Age } \\
\hline $8-24$ & Reference & \\
\hline $25-44$ & 1.162 & -0.409 \\
\hline $45-64$ & 1.596 & -0.578 \\
\hline 65 and more & 1.797 & -0.788 \\
\hline \multicolumn{3}{|l|}{ Educationt } \\
\hline Without formal education & $3.300^{*}$ & -2.382 \\
\hline Primary & $3.441^{* *}$ & -1.955 \\
\hline Middle school & 1.770 & -0.989 \\
\hline High school & 1.141 & -0.632 \\
\hline University and postgraduate & Reference & \\
\hline \multicolumn{3}{|l|}{ Employment status } \\
\hline Employed & Reference & \\
\hline Inactive & 1.380 & -0.377 \\
\hline Unemployed & 1.299 & -0.586 \\
\hline \multicolumn{3}{|l|}{ Smoking intensity } \\
\hline Daily cigarette consumption & $1.098^{* *}$ & -0.045 \\
\hline Daily cigarette consumption ${ }^{2}$ & 0.998 & -0.002 \\
\hline \multicolumn{3}{|l|}{ Socioeconomic levelł } \\
\hline High & Reference & \\
\hline Medium & 0.560 & -0.217 \\
\hline Low & 1.450 & -0.544 \\
\hline \multicolumn{3}{|l|}{ City } \\
\hline Mexico City & Reference & \\
\hline Guadalajara & 1.668 & -0.655 \\
\hline Monterrey & 1.577 & -0.64 \\
\hline Hermosillo & 1.209 & -0.585 \\
\hline Leon & $3.743^{* * *}$ & -1.427 \\
\hline Merida & $2.560^{* *}$ & -1.07 \\
\hline Durango & $3.883^{* * *}$ & -1.426 \\
\hline Veracruz & 0.363 & -0.281 \\
\hline Observations & 2269 & \\
\hline
\end{tabular}

${ }^{*} \mathrm{P}<0.1 ;{ }^{* *} \mathrm{P}<0.05 ;{ }^{* * *} \mathrm{P}<0.01$.

†Education corresponds to the last grade completed.

$\ddagger$ To build the socioeconomic level indicator, the Mexican Association of Market Research Agencies $8 \times 7$ method was used, which consists of assigning scores based on eight variables on characteristics of the household (number of rooms, number of bathrooms, whether there is a shower in any of the bathrooms, number of light bulbs, floor type, number of cars, whether the household has a gas or electric stove) and the head of the household (highest grade completed) collected with the survey of smokers. ${ }^{41}$

no differences were found in most cities and the differences found in two cities (Merida and Veracruz) were small and not statistically significant $(\mathrm{p}>0.05)$. This suggests that our method, which evaluates the packs' visible characteristics, even among the packs with one or more characteristics not visible due to the pack damage, is valid. Moreover, we compared the classification based on the three pack characteristics to the classification based on the cigarette brand using the packs from the littered study. Again, classifying the cigarettes as not intended for the Mexican market based on missing pack features and based on the cigarette brand yielded similar results $(p>0.05$, online supplementary appendix table $\mathrm{S} 4$ ). This suggests that the method of classifying cigarettes based on their brand, used for the data from the survey of smokers, is also statistically valid.
The correlates of illicit cigarette consumption were analysed using survey data and logistic regression (table 3). Smokers with low levels of education (primary or less), as well as smokers with higher consumption levels, have greater odds of smoking illicit cigarettes, a finding consistent with previous studies. ${ }^{38}$ Also, smokers from Durango, Leon and Merida have higher odds of smoking illicit cigarettes compared with Mexico City, after controlling for demographics and intensity of consumption. Future studies should investigate potential drivers of the differences in illicit trade penetration across the country. Other covariates, namely gender, age, employment and socioeconomic level status, were not associated with illicit cigarette consumption.

As expected, self-reported average prices of illicit cigarettes were lower than their legal counterparts, particularly in the case of those sold per pack (1.5 pesos vs 2.3 pesos per cigarette, respectively), which is the most common form of purchase among illicit cigarette users (nearly 90\%). This may explain the higher odds of illicit cigarette consumption among smokers with less education and higher intensity of consumption.

More details on the study methods and findings can be found in the full study report. ${ }^{39}$

\section{DISCUSSION}

This study suggests that the proportion of cigarettes not intended for the Mexican market is larger when measured using the collection of littered packs compared with when measured using the survey of smokers. Consistent with findings from Poland by Stoklosa and Ross, ${ }^{18}$ we find this difference to be relatively small (at ca. 1 percentage point) and only borderline statistically significant overall.

The two estimates for various cities were statistically different, however. There might be several factors that contribute to this difference between the estimates. First, in the survey of smokers, some of the surveyed individuals might not be willing to reveal their use of illicit cigarettes. While this is measured with an indirect question about brands, which should mitigate this challenge, this might lead to under-reporting of illicit cigarettes in those surveys. In fact, if we take the subsample of smokers who showed a pack at the moment of the interview and had complete information $(n=674)$, the share of illicit cigarette consumption is $5.9 \%(n=40)$ if self-reported information of brand is employed and 7.3\% $(n=49)$ if the brand observed in the pack is employed. Second, those who litter cigarettes might also be more likely to smoke illicit cigarettes, as the engagement in those two activities might be linked. If that was the case, the littered pack collection would overestimate illicit cigarette use. While a previous study for the USA that compared littered packs with properly disposed packs found little evidence of an association between littering and tax avoidance, ${ }^{15}$ more research is needed to assess whether this may be a potential source of bias in Mexico. Third, the single stick users, who are more likely to be captured in the survey of smokers compared with the survey of littered packs, could be less likely to use illicit cigarettes. This last hypothesis seems to be supported by our data, which finds that only $2.2 \%$ of smokers of single sticks who took part in our survey reported buying illicit brands as their last purchase, compared with 5.5\% among those who purchased cigarette packs. While further research is needed to better understand this difference, as single stick buyers are willing to pay a much higher price per unit, they may also be more likely to look for traditional licit brands. Fourth, if the single stick vendors predominantly properly dispose their empty cigarette packs, then the survey of littered packs would overestimate illicit trade, because it would oversample the smokers 
who buy cigarettes in packs, who are also more likely to smoke illicit cigarettes.

Both methods, the survey of smokers and the littered pack collection have other limitations, which are discussed at length elsewhere. $^{14} 18$ Among those limitations, the inability of the littered pack collection to distinguish between illicit packs and non-domestic packs that were purchased outside of the country or in the tax-free zones and brought to the country within legal limits is a potentially significant limitation. However, the findings from our survey of smokers suggest that cigarette purchasing from outside the country is not large. Only 2 out of the 2396 smokers $(0.08 \%)$ reported purchasing their last cigarettes in a tax-free zone, while none reported purchasing them in another country. Outside of Mexico City and Merida, the cities sampled were not relatively important tourist destinations. Also, cities very near either the northern or southern border were not included in the sample. Therefore, the packs classified as not intended for the Mexican market in our study are likely to be truly illicit.

Our findings suggest that the optimal practice for researchers studying illicit trade is to cross validate their estimates using both survey methods: the smoker survey and the littered pack survey. However, this research also suggests that when resources are limited, researchers could use either of the methods because both yield very similar results, as long as the researchers consider the possible biases of each method. The survey of littered packs is usually less expensive compared with the survey of smokers, as it does not require skilled data collectors in the field and the pack information can be coded in a research office after collection.

Finally, our study provides a transparent and replicable estimate of illicit trade in Mexico. Although the sample was not designed to be nationally representative, the large number of cities and smokers in our study, their geographical distribution-a thorough coverage of different areas in each city, and the characteristics of smokers surveyed in our study, which resemble those for typical smokers in the country, allow us to infer a robust, national-level estimate of the illicit trade. The estimates of illicit trade presented by the tobacco industry are nearly twice as high as those from our study. This finding is, again, consistent with findings from other studies, ${ }^{12}$ which suggest that the tobacco industry is exaggerating the scope of the illicit trade problem.

\section{CONCLUSIONS}

This study shows that the survey of smokers and the littered pack collection, two methods broadly used to estimate the scope of illicit trade, yield similar results on average. Therefore, researchers who cannot afford to implement both types of studies can consider using either method. This study also invalidates the recent estimates of the illicit trade provided by the tobacco industry in Mexico and shows that those estimates are nearly twice as high as those from a transparent and replicable academic study, suggesting strongly that the Mexican government should not heed tobacco industry exhortations of a large and growing illicit cigarette market. To mitigate any illicit trade problem, Mexico should soon ratify the Protocol to Eliminate Illicit Trade in Tobacco Products and implement its provisions, including an industry-independent tracking and tracing system to control local production and legal imports, ${ }^{50}$ but more importantly, mechanisms to combat illicit imports. The government should also continue implementing all provisions of WHO FCTC, including significantly raising cigarette excise taxes. Tobacco control measures that lead to lower demand for tobacco products overall will also lead to a smaller illicit cigarette problem in the long term as demand for all types of products will decline.
What this paper adds

- The tobacco industry has strong incentives to overstate the scope of the illicit cigarette trade. The threat of illicit trade has been successfully employed worldwide to impede progress in tobacco control, especially tobacco tax increases.

- A growing number of academic studies have consistently exposed serious methodological problems in industry-funded estimates. Other academic studies that employ one of the proven methods to estimate the illicit trade-gap analysis, empty pack survey and surveys of smokers - have shown that their estimates are generally lower than those of the tobacco industry. However, little is known about how the estimates from different methods compare.

- This study estimated the scope of illicit cigarette trade in eight major cities in Mexico using the two survey methods. The results suggest that the optimal practice is to cross validate the estimates using both methods, but either could be used if resources are limited, as both yield similar results on average. Consistent with previous studies, our estimates were also much lower than those of the industry.

Correction notice This paper has been updated since first published to update the funding statement.

Contributors BSdMJ and LMR-S conceived and designed the study and conceptualised the analytic approach. MS, KW and JD advised on study design and analytic approach. BSdMJ conducted the statistical analyses. MS wrote the initial draft of the manuscript. BSdMJ, LMR-S, KW and JD provided substantial contributions to the writing and finalising of the manuscript.

Funding This work was supported by an agreement with Johns Hopkins University with funds from the Bloomberg Philanthropies and additional support from the American Cancer Society (ACS\#49080) and the Pan American Health Organization (SCON2017-02674).

Competing interests None declared.

Patient consent for publication Not required.

Provenance and peer review Not commissioned; externally peer reviewed.

Data availability statement Data are available upon reasonable request. Unpublished data from the study are available to other researchers upon reasonable request to the corresponding author by email.

Open access This is an open access article distributed in accordance with the Creative Commons Attribution Non Commercial (CC BY-NC 4.0) license, which permits others to distribute, remix, adapt, build upon this work non-commercially, and license their derivative works on different terms, provided the original work is properly cited, appropriate credit is given, any changes made indicated, and the use is non-commercial. See: http://creativecommons.org/licenses/by-nc/4.0/.

\section{ORCID iDs}

Belen Saenz de Miera Juarez http://orcid.org/0000-0003-3117-0734

Michal Stoklosa http://orcid.org/0000-0003-2014-539X

Kevin Welding http://orcid.org/0000-0002-1833-6691

\section{REFERENCES}

1 Scollo M, Zacher M, Coomber K, et al. Use of illicit tobacco following introduction of standardised packaging of tobacco products in Australia: results from a national cross-sectional survey. Tob Control 2015;24:ii76-81.

2 Savell E, Gilmore AB, Fooks G. How does the tobacco industry attempt to influence marketing regulations? A systematic review. PLoS One 2014;9:e87389.

3 Stoklosa M. No surge in illicit cigarettes after implementation of menthol ban in nova Scotia. Tob Control 2019;28:702-4.

4 Philip Morris International. Annual meeting of stockholders. New York, NY: PMI, 2010. http://phx.corporate-ir.net/External.File?item=UGFyZW50SUQ9NDU4NDB8Q2hpbGRJ RDOtMXxUeXBIPTM=\&t=1

5 Drope J, Schluger N, Cahn Z. The tobacco atlas. 6th Edn. Atlanta: American Cancer Society and Vital Strategies, 2018.

6 Smith KE, Savell E, Gilmore AB. What is known about tobacco industry efforts to influence tobacco Tax? A systematic review of empirical studies. Tob Control 2013;22:e1 
7 Fooks GJ, Peeters S, Evans-Reeves K. Illicit trade, tobacco industry-funded studies and policy influence in the EU and UK. Tob Control 2014;23:81-3.

8 Crosbie E, Bialous S, Glantz SA. Memoranda of understanding: a tobacco industry strategy to undermine illicit tobacco trade policies. Tob Control 2019;28:e110-8.

9 Joossens L, Gilmore AB, Stoklosa M, et al. Assessment of the European Union's illicit trade agreements with the four major transnational tobacco companies. Tob Control 2016;25:254-60.

10 Rowell A, Evans-Reeves K, Gilmore AB. Tobacco industry manipulation of data on and press coverage of the illicit tobacco trade in the UK. Tob Control 2014;23:e35-43.

11 Gilmore AB, Fooks G, Drope J, et al. Exposing and addressing tobacco industry conduct in low-income and middle-income countries. Lancet 2015;385:1029-43.

12 Gallagher AWA, Evans-Reeves KA, Hatchard JL, et al. Tobacco industry data on illicit tobacco trade: a systematic review of existing assessments. Tob Control 2019;28:334-45.

13 Smith J, Thompson S, Lee K. 'Both sides of the argument'? A critical review of existing evidence on the illicit trade in tobacco products in Canada. Tob Control 2019;28:e141-7.

14 Ross H. Understanding and measuring cigarette Tax avoidance and evasion: a methodological guide, 2015. Available: https://tobacconomics.org/wp-content/ uploads/2015/03/Ross_Methods_to_Measure_Illicit-Trade_03-17-15.pdf [Accessed 4 Mar 2017].

15 Merriman D. The Micro-Geography of Tax avoidance: evidence from Littered cigarette packs in Chicago. Am Econ J Econ Policy 2010;2:61-84.

16 John RM, Ross H. Illicit cigarette sales in Indian cities: findings from a retail survey. Tob Control 2018;27:684-8.

17 Bialous SA, Glantz SA. The challenges of monitoring illicit trade should not obscure the success of tobacco Tax policy. Am J Public Health 2018;108:161-3.

18 Stoklosa M, Ross H. Contrasting academic and tobacco industry estimates of illicit cigarette trade: evidence from Warsaw, Poland. Tob Control 2014;23:e30-4.

19 World Health Organization. Who global report on trends in prevalence of tobacco smoking 2000-2025. 2nd edn. Geneva, Switzerland: World Health Organization, 2018.

20 World Health Organization. Who global report on trends in prevalence of tobacco smoking 2015. Geneva, Switzerland: World Health Organization, 2015. http://apps. who.int/iris/handle/10665/156262

21 Goodchild M, Nargis N, Tursan d'Espaignet E. Global economic cost of smokingattributable diseases. Tob Control 2018:27:58-64.

22 U.S. National Cancer Institute and World Health Organization. The economics of tobacco and tobacco control. National cancer Institute tobacco control monograph 21. Bethesda, MD: U.S. Department of Health and Human Services, National Institutes of Health, National Cancer Institute and World Health Organization, 2016.

23 Jiménez-Ruiz JA, Sáenz de Miera B, Reynales-Shigematsu LM, et al. The impact of taxation on tobacco consumption in Mexico. Tob Control 2008;17:105-10.

24 Waters H, Sáenz de Miera B, Ross H, et al. The economics of tobacco and tobacco taxation in Mexico. Paris: International Union Against Tuberculosis and Lung Disease, 2010.
25 Economist Intelligence Unit. World cost of living survey. London, UK: Economist Intelligence Unit, 2019.

26 Euromonitor International. Passport database. London, UK: Euromonitor, 2019.

27 International Monetary Fund. World economic outlook database, 2019. Available: http://www.imf.org [Accessed 3 Jan 2019].

28 United Nations Population Division. World population prospects, 2019. Available: https://population.un.org/wpp/Download/Standard/Population/ [Accessed $20 \mathrm{Apr}$ 2019].

29 Confederacion de Camaras Industriales (CONCAMIN). Cigarros ilegales en Mexico, 2012.

30 Blecher E, Liber A, Ross $\mathrm{H}$, et al. Euromonitor data on the illicit trade in cigarettes. Tob Control 2015;24:100-1.

31 Sáenz de Miera Juárez B, Zúñiga Ramiro J. Comercio ilícito de productos de tabaco en México: evidencia disponible y legislación vigente. In: Reynales Shigematsu LM, Thrasher JF, Lazcano Ponce E, eds. Salud pública Y tabaquismo, volumen I. Políticas para El control del tabaco en México. Cuernavaca, México: Instituto Nacional de Salud Pública, 2013.

32 Instituto Nacional de Psiquiatría Ramón de la Fuente Muñiz, Instituto Nacional de Salud Pública, Comisión Nacional Contra las Adicciones, Secretaría de Salud. Encuesta Nacional de Consumo de Drogas, Alcohol y Tabaco 2016-2017: Reporte de Tabaco. Mexico City: INPRFM, 2017.

33 Instituto Nacional de Estadística y Geografía. Marco geoestadístico 2010 (Censo de Población Y Vivienda 2010). Aguascalientes: INEGI, 2010. https://www.inegi.org.mx/ app/biblioteca/ficha.html?upc=702825292805

34 Ley General para el Control del Tabaco. Official Gazette of the Federation (Diario Oficial de la Federacion or DOF). Available: http://www.conadic.salud.gob.mx/pdfs/ ley_general_tabaco.pdf

35 Servicio de Administración Tributaria (SAT). Anexo 11 de la Resolución Miscelánea fiscal, 2017.

36 Comisión federal para La Protección Contra Riesgos Sanitarios (Cofepris), 2017. Available: https://www.gob.mx/cofepris/acciones-y-programas/alertas-sanitarias

37 Sáenz de Miera Juárez B, Thrasher JF, Reynales Shigematsu LM, et al. Tax, price and cigarette brand preferences: a longitudinal study of adult smokers from the ITC Mexico survey. Tob Control 2014;23 Suppl 1:i80-5.

38 Paraje G, Araya D, Drope J. Illicit cigarette trade in metropolitan Santiago de Chile. Tob Control 2020;29:68-73

39 Sáenz de Miera Juárez B, Reynales Shigematsu LM. El consumo de cigarros ilícitos en México. Una estimación robusta Y transparente para apoyar La toma de decisions. Atlanta: American Cancer Society, 2019.

40 Nargis N, Stoklosa M, Ikamari L, et al. Cigarette taxation in Kenya at the crossroads: evidence and policy implications. Waterloo: University of Waterloo, 2015

41 Asociacion Mexicana de Agencias de Inteligencia de Mercado y Opinion. Nivel Socio Economico AMAI 2018. Mexico City: AMAl, 2017. http://www.amai.org/nse/wpcontent/uploads/2018/04/Nota-Metodológico-NSE-2018-v3.pdf 